\title{
Correction to: Advances in Natural Computation, Fuzzy Systems and Knowledge Discovery
}

Hongying Meng, Tao Lei, Maozhen Li, Kenli Li, Ning Xiong, and Lipo Wang

\section{Correction to:}

H. Meng et al. (Eds.): Advances in Natural Computation, Fuzzy Systems and Knowledge Discovery, AISC 1348, https://doi.org/10.1007/978-3-030-70665-4

Due to a technical error, the original version of the book was published under the Advances in Intelligent Systems and Computing series. The book series has been changed from Advances in Intelligent Systems and Computing to Lecture Notes on Data Engineering and Communications Technologies. 